\title{
Effect of friction stir welding and post-weld heat treatment on a nanostructured ferritic alloy
}

\author{
B. Mazumder, ${ }^{1}$ X. Yu, ${ }^{2}$ P. D. Edmondson, ${ }^{2}$ C. M. Parish ${ }^{2}$, M. K. Miller, ${ }^{1}$ H. M. Meyer III ${ }^{2}$ and Z. Feng ${ }^{2}$ \\ ${ }^{1}$ Center for Nanophase Materials Sciences, Oak Ridge National Laboratory, Oak Ridge, TN 37831 \\ ${ }^{2}$ Materials Science and Technology Division, Oak Ridge National Laboratory, Oak Ridge, TN 37831
}

\begin{abstract}
Nanostructured ferritic alloys (NFAs) are new generation materials for use in high temperature energy systems, such as nuclear fission or fusion reactors. However, joining these materials is a concern, as their unique microstructure is destroyed by traditional liquid-state welding methods. The microstructural evolution of a friction stir welded 14YWT NFA was investigated by atom probe tomography, before and after a post-weld heat treatment (PWHT) at $1123 \mathrm{~K}$. The particle size, number density, elemental composition, and morphology of the titanium-yttrium-oxygenenriched nanoclusters (NCs) in the stir and thermally-affected zones were studied and compared with the base metal. No statistical difference in the size of the NCs was observed in any of these conditions. After the PWHT, increases in the number density and the oxygen enrichment in the NCs were observed. Therefore, these new results provide additional supporting evidence that friction stir welding appears to be a viable joining technique for NFAs, as the microstructural parameters of the NCs are not strongly affected, in contrast to traditional welding techniques.
\end{abstract}

Keywords: Friction stir weld, Nanostructured ferritic alloys, Atom probe tomography

\section{Contact Information}

Dr. Baishakhi Mazumder,

Center for Nanophase Materials Sciences, Oak Ridge National Laboratory,

P.O. Box 2008, Oak Ridge, TN 37831-6139, USA

E-mail: mazumderb@ornl.gov; Phone: +1-865-576-6994

This manuscript has been authored by UT-Battelle, LLC under Contract No. DE-AC05-00OR22725 with the U.S. Department of Energy. The United States Government retains and the publisher, by accepting the article for publication, acknowledges that the United States Government retains a non-exclusive, paid-up, irrevocable, world-wide license to publish or reproduce the published form of this manuscript, or allow others to do so, for United States Government purposes. The Department of Energy will provide public access to these results of federally sponsored research in accordance with the DOE Public Access Plan (http://energy.gov/downloads/doe-public-access-plan). 


\section{Introduction}

Nanostructured ferritic alloys (NFAs), such as 14YWT (Fe-14Cr-3W(wt.\%) base ODS steel with additions of $\mathrm{Ti}$ and $\mathrm{Y}$ ), are considered promising candidate materials for structural materials in fusion reactors and cladding materials of future advanced fast reactors, due to their high temperature creep properties and tolerance to high-dose radiation. [1-2] The excellent creep resistance and the radiation resistance of these alloys are mainly due to the high number density of ultrafine Ti-Y-O enriched nanoclusters (NCs) and ultrafine grain size $(<500 \mathrm{~nm})$ [3-5]. In particular, oxide dispersion strengthened (ODS) steels (and by extension NFAs), are strong candidate materials for fusion blanket designs. [7-9] Blankets will have complex piping and other fabrication requirements and will require a means to weld NFAs to NFAs and NFAs to other steels, especially considering the difficulty in making large monolithic sections from NFAs. This is difficult because NFAs are produced by a mechanical alloying (MA) process to force the $\mathrm{Y}$ and $\mathrm{O}$ from the $\mathrm{Y}_{2} \mathrm{O}_{3}$ powder into solid solution, in order to form ultrafine Ti-Y-O NCs upon subsequent thermal processing steps [6]. Due to this requirement to use the MA process to fabricate these alloys (rather than conventional casting) [10], it is not technically feasible to produce complex, or large-scale, components. Therefore, there is a requirement to develop joining techniques for similar and dissimilar materials for NFAs, e.g. 14YWT-14YWT; and 14YWT-F82H. Currently, the lack of any joining technique that maintains the properties of welded structure as good as base metal limits the application of these alloys. Conventional fusion (liquid-state) welding destroys the fine dispersion of oxide particles, causes grain coarsening, and modifies the dislocation structures in the alloy [11-12] and so is not applicable. Hence, solidstate methods must be used. Friction Stir Welding (FSW) has been considered to be a favorable technique to weld NFA alloys, while preserving the advantageous microstructure [12-14]. FSW uses a high-strength rotating tool inserted into the workpiece to make a joint without melting, which gives a strong weldment with minimum degradation of the microstructure and microscopic properties.

An important question that must be answered is how the microstructure and chemical composition of the ultrafine dispersoids is modified after the FSW process. A variety of studies 
have been carried out, including electron microscopy [9, 12,14-15], to identify NC coarsening and their distribution throughout the weld zone $[12,9,16]$. During the FSW process in the stir zone, the original microstructure of the work piece is affected both by heat and plastic deformation, and a modified oxide-dispersed microstructure formed. Different zones, namely base metal (BM), stir zone (SZ), thermo-mechanically affected zone (TMAZ), and heat-affected zone (HAZ) are usually reported. [17] These modified microstructures from the different regions of welded sample need to be evaluated for their chemical and structural morphology in order to understand the related material properties, particularly how the NCs are modified and how their morphology/chemical compositions are altered. This information will help explain the overall macro-scale properties of the material, gauge the effective quality of the weld, and the suitability of the joint for nuclear applications.

Previous research has proven that FSW is a viable technique to join ODS alloys, including NFAs [18-21]. ODS alloys, such as MA956, showed significant coarsening of the oxides after FSW, and concomitant loss of strength in the SZ [19-20]. In NFAs 14YWT, small NCs were observed after the FSW, and showed significant variations in hardness across the FSW [21]. Atom Probe Tomography (APT) has been successfully used to provide detailed structural information, such as the particle size and distribution, number density, and the composition of these nanostructures from the different zones. Both coarser-structured ODS alloys [22] and finer-structured NFAs [21] have shown modification of the precipitates after welding and post-weld heat treatment (PWHT). The microstructure in the SZ and TMAZ shows fine ferrite grains with high densities of ultrafine Ti-Y-O-enriched precipitates [21-22]. However, due to heat and deformation induced by the FSW process, SZ and TMAZ also showed non-uniform distribution of NCs, which result in a reduction of strength in these regions. It should be noted that, as the studies above used different FSW process conditions, the difference in the observed stability of the nano-sized precipitates could also be attributed to the variation in temperature and deformation in these experiments, in addition to the difference in the types of the nanoprecipitates. As PWHT is a standard procedure for weld strength recovery, the current study examines the effect of PWHT on the microstructure of FSW 14YWT NFA. 


\section{Experimental procedure}

The material examined in this investigation was a 14YWT NFA [23]. The 14YWT NFA was produced by a mechanical alloying process by ball milling pre-alloyed $\mathrm{Fe}-14 \mathrm{Cr}-3 \mathrm{~W}-0.4 \mathrm{Ti}$ powder with 0.3 wt. $\% \mathrm{Y}_{2} \mathrm{O}_{3}$ powder. The resultant powder was subsequently degassed in a sealed steel can at $673 \mathrm{~K}$ and extruded at $1123 \mathrm{~K}$ into a rod. The rod was then annealed at 1273 $\mathrm{K}$ for $1 \mathrm{~h}$ and fabricated into plate by rolling to $40 \%$ reduction in thickness, $2.86 \mathrm{~mm}$, at $1123 \mathrm{~K}$ [21]. The bulk composition of this material is shown in Table 1.

The friction stir welding was conducted in a MTS ISTRI friction stir machine with a polycrystalline cubic boron nitride (PCBN) pin, as shown schematically in Fig 1. The PCBN pin had a shoulder diameter of $16 \mathrm{~mm}$ with a threaded, nominally $6 \mathrm{~mm}$ diameter, pin. The length of the pin was $3 \mathrm{~mm}$, i.e., slightly longer than the thickness of the 14YWT plates. A $2.86 \mathrm{~mm}$ thick plate of $\mathrm{F} 82 \mathrm{H}$ steel with a nominal composition shown in Table 1 was used as a support substrate. The tool had a rotation speed of $300 \mathrm{rpm}$ and traverse rate at $7.62 \mathrm{~cm}$ per min. The rotating pin tool traveled parallel to the extrusion and rolling directions of the 14YWT specimens, as shown in the previous work [21]. Part of the resulting FSW sample was then PWTH at $1123 \mathrm{~K}$ for $2 \mathrm{~min}$.

APT specimens were prepared from site-specific locations in the SZ, TMAZ and BM from both the as-FSW and PWHT samples with a FEI Nova 200 Focused Ion Beam ion miller. The specimens were analyzed in a CAMECA Instruments Inc. Local Electrode Atom Probe (LEAP 4000X HR) in pulsed-laser mode. The data was collected from specimens that were cooled to a temperature of $30 \mathrm{~K}$ under ultrahigh vacuum $\left(<10^{-11} \mathrm{mbar}\right)$. To achieve controlled field evaporation, short-duration, ultraviolet (UV) laser pulses with laser energy of $100 \mathrm{pJ}$ were focused on the apex region of the specimen. Note that the diameter of the laser beam was significantly larger than the apex region of the APT specimen, so not all this energy was introduced into the specimen. A pulse repetition frequency of $200 \mathrm{kHz}$ and a detection rate of 0.005-0.01 atoms per pulse were also used. Data reconstruction and analysis were performed with the CAMECA Instruments Inc. IVAS (version 3.6.6). Atom probe tomography was performed on the three regions BM, SZ and TMAZ, before and after heat treatment $(\mathrm{HT})$ for a structural comparison. 
The volumes of the Ti-Y-O precipitates, estimated from the isosurface are converted to the effective radii using the equation, $r_{\text {eff }}=\sqrt[s]{3 V / 4 \pi}$, assuming spherical geometry. The number densities were estimated from the number of fully-contained plus half the partially-contained precipitates within the volume, the number of ions in the assigned peaks of the mass spectra, the detection efficiency of the mass spectrometer $(37 \%)$ and the volume of the standard 2 atom body-centered cubic unit cell of Fe [24].

X-ray photoelectron spectroscopy (XPS) was performed with a Thermo Scientific Model KAlpha XPS instrument. The instrument utilizes monochromated Al $\mathrm{K}_{\alpha}$ X-rays (1486.6 eV) focused to a $400 \mu \mathrm{m}$ spot size for maximum signal and to obtain an average surface composition over the largest possible area. The instrument has a hemispherical electron energy analyzer equipped with a 128 multi-channel detector system. Base pressure in the analysis chamber is typically $2 \times 10^{-9}$ mbar or lower. Samples were mounted to the sample platen using metal clips and an area within the weld zone was analyzed on each sample. Survey spectra $(0-1350$ eV) were acquired for qualitative and quantitative analysis of the as received sample surfaces. Compositional depth profiles were measured using a monotonic Ar-ion gun operated at $2 \mathrm{kV}$ and alternatively sputter etching the sample and acquiring the core level spectra for Fe $2 \mathrm{p}, \mathrm{Cr} 2 \mathrm{p}, \mathrm{O}$ 1s, and C 1s. Data were collected and processed using the Thermo Scientific Avantage XPS software package (v 4.61).

\section{Results}

\subsection{Morphology and structural analysis}

A cross-sectional view of the microstructures of the as-received 14YWT-F82H FSW sample observed by scanning electron microscopy (SEM) is shown in Fig 2. Three distinct regions (BM, TMAZ, SZ) are analyzed. According to the reported results [17,25], peak temperature experienced in the SZ of steels could be as high as $1373 \mathrm{~K}$.

The distribution of Ti-Y-O-enriched precipitates with 5 at. \% Ti concentration isosurface (green), in the as-FSW BM, SZ, and TMAZ are shown in Fig. 3. The BM exhibits a uniform distribution of both spheroidal and elongated NCs, Fig 3a, in agreement with previous work [21,26]. The distributions of precipitates in the SZ and TMAZ, Fig 3b and 3c, respectively, exhibit some inhomogeneity with some NCs aligned along the flow direction of the weld. A low number 
density of $\mathrm{Ti}(\mathrm{O}, \mathrm{C}, \mathrm{N})$ precipitates are identified and indicated by the brown 5 at. $\% \mathrm{Ti}$ concentration isosurface. These $\sim 10 \mathrm{~nm}$ to $\sim 100 \mathrm{~nm}$ precipitates were preferentially located in the grain boundaries [27] or intragranular positions in the ferrite matrix, as previously observed.

The distributions of NCs in the PWHT samples for three different zones are shown in Fig 4. After the PWHT, the base metal exhibits a homogenous distribution of NCs similar to the asFSW condition: no significant change was observed. Similarly, some inhomogeneities in the TiY-O-enriched NC distribution, along with some coarser precipitates, were observed both in the TMAZ and SZ, which were similar to as-FSW condition.

The average number densities of the precipitates are reported in Table 3. Significantly, although no change in the average number densities of the precipitates in the BM between the as-received and PWHT conditions were observed, the number densities in the SZ had increased by an order of magnitude in the PWHT condition, and the TMAZ by about 50\%. The FSW process appears to dissolve some of the NCs, leaving the isolated solute atoms in the matrix, or perhaps as NCs too small to be detected with the $37 \%$ efficiency of the detector in the atom probe. Following PWHT, there is an increase in the number density of these NCs detected.

The statistical information on the size distributions of the NCs is given in Table 3 for both conditions. Although the mean radius appeared to increase slightly in the SZ and TMAZ compared to the BM in both the as-FSW, and to a smaller extent, in the PWHT conditions, the large standard deviations indicated that there were no statistical differences between any of the size estimates. Coarsening of NCs or oxide particles has been observed in the SZ of different ODS ferritic steels due to severe plastic deformation and complex material flow [12, 28-29]. The normalized size distributions of precipitates are shown in Fig 5 for all the three zones and both conditions. These results indicate that there are some differences in the shape of the size distributions. A detailed comparison of the size distribution from the SZ for the as-FSW and PWHT is shown in Fig 6. The as-FSW distribution is more skewed than the PWHT distribution (Table 4). The nature of particle distribution is not Gaussian but leptokurtic.

\subsection{Chemical analysis}

The overall average compositions of the three regions shown in Fig 3 and Fig 4 are reported in Table 5. These composition estimates do not deviate significantly from the bulk alloy 
composition (Table 1), indicating that there was no intermixing from the lower $\mathrm{Cr} F 82 \mathrm{H}$ alloy. In the volumes from the PWHT specimen, Fig 4, a similar trend in the composition was observed, as shown in Table 5. However, the oxygen content was found to increase after the PWHT in all the analyzed volumes. The $\mathrm{Y}:(\mathrm{Ti}+\mathrm{O})$ ratio, as estimated from the bulk composition in the BM, SZ and TMAZ before and after PWHT, is reported in Table 6. This ratio in BM and SZ was found to be lower after PWHT indicating the oxygen enrichment due to PWHT. However, $\mathrm{Y}:(\mathrm{Ti}+\mathrm{O})$ ratio in the TMAZ does not show any variance after the PWHT.

Proximity histograms showing the averaged concentration variation across the matrix-NC interface for the three regions after the PWHT for two size ranges of the NCs, i.e., 2-4 nm and 4$6 \mathrm{~nm}$, are shown in Fig 7. The smaller 2-4 nm range of NCs exhibited $\mathrm{Cr}$ enrichment at the matrix-NC interface followed by a decrease from the matrix level in the interior of NCs in the SZ and TMAZ but this $\mathrm{Cr}$ decrease was not as evident in the BM. This $\mathrm{Cr}$ enrichment at the interface was not evident in the larger NCs. The larger NCs were only observed in the SZ and TMAZ. These larger NCs appear to contain more oxygen (up to $235 \%$ ) and Y (up to $\approx 15 \%$ ) in their interiors than the smaller 2-4 nm NCs. However, it should be noted that trajectory aberrations may lead to lower solute concentrations in the smaller NCs, and as such the observed difference may be larger than the observed value. To compensate for these solute enrichments, the $\mathrm{Cr}$ level was lower in the interior of the larger 4-6 nm NCs. The ensemble compositions of the NCs, based on the total number of atoms within the volumes extracted from the interior of all the isosurfaces for the three conditions and the two size ranges of NCs, are shown in Table 7. Broadly, the differences in the compositions for 2-4 nm vs 4-6 nm NCs in the PWHT material are minor, although the larger NCs had slightly higher oxygen contents. The $\mathrm{Y}:(\mathrm{Ti}+\mathrm{O})$ ratios from 5 individual NCs were measured from all the samples and are shown in Table 8. These estimates show variations in the ratio between the individual NCs. Therefore, the trend of the averages of these $5 \mathrm{NC}$ between the as-FSW and the PWHT conditions is difficult to conclusively discern. 


\section{Discussion}

\subsection{Coarsening of the NCs during FSW process}

One of the significant observations from the APT measurements is the coarsening and/or elongation of the NCs existing in the material. This coarsening is attributed to a change in localized solute and vacancy environments around the NCs.

The NCs form during precipitation of the solute atoms $(\mathrm{Y}, \mathrm{Ti}, \mathrm{O})$ from the solute-enriched asmechanically-alloyed matrix during the soak prior to extrusion, and during the hot extrusion process. Irradiation [30-32] has previously shown that the NCs are destroyed by mixing back into the matrix; at higher temperatures, sufficient kinetics are available to cause re-formation of the NCs from the solute- and vacancy-enriched regions around the cascade affected zone resulting from a displacement cascade [33]. It appears that the severe mechanical deformation and short-term localized heating of FSW may be causing a similar dissolution processes.

After the PWHT, there is approximately a 10x increase of number density in the SZ compared to the as-FSW condition, and approximately a $\sim 4 \times$ increase of number density compared to the base metal (Table 3). This increase is indicative of the nucleation of new NCs. It is important to note the insignificant change in number density in the BM caused by PWHT, indicating the BM is highly stable. In the SZ, either the solute in the solid solution is nucleating into new NCs during PWHT process and/or clusters below the resolution limit (due to a combination of the $37 \%$ ion detection efficiency and the voxelization process used) are growing during the PWHT. In either case, the increase in number density of small NCs would result in a reduction in average size of the NCs (with little effect on maximum size).

It seems likely that the increased number density and reduced mean size in the SZ after the PWHT could modify the mechanical and radiation-resistance properties, relative to the base metal. The increase in number density will probably be beneficial to radiation tolerance [34], assuming that the processing has not changed the NCs' identity or interface structure (and thus sink bias or saturability) significantly. Creep properties could conceivably be improved [35]. The extremely high density, however, may cause a loss of ductility or toughness due to increased dislocation pinning. Given that the $14 \mathrm{Cr}$ type NFAs' toughness properties are already not optimal [23], this is potentially detrimental. 
In addition to coarsening, the NCs are both elongated and form into bands or filaments of multiple NCs (Fig. 3b). This is an effect of the mechanical deformation, but cannot yet be described. Regardless, this preferential orientation of NCs is also likely to result in variations in mechanical properties and will require optimization of joining parameters to control.

\subsection{Oxygen enrichment in PWHT}

The increase in bulk oxygen content in the NCs PWHT may modify both mechanical and irradiation-tolerance properties. Because all three zones (BM, FSW, and TMAZ) showed increased oxygen content (Table 5 and Table 7), oxygen pickup appears to be due to the PWHT, as opposed to the FSW process per se.

Between the BM and the SZ and TMAZ, however, some differences are observed. Significantly higher oxygen content is seen in the NCs after the PWHT in the SZ and TMAZ compared to the bulk (Figure 7), particularly for the larger (4-6 nm) clusters (Table 6). Although a firm explanation for the increase in NC oxygen in the SZ and TMAZ compared to the BM is not yet possible, several hypotheses can be proposed for future study.

The FSW process introduces significant deformation and accompanying stored energy and

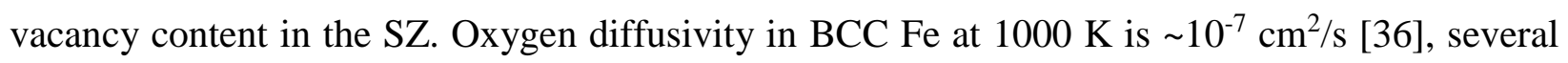
orders of magnitude higher than Fe self-diffusion at these temperatures $\left(\sim 10^{-11} \mathrm{~cm}^{2} / \mathrm{s}\right.$ [37] $)$, so preferential diffusion of the oxygen atoms is expected, although binding of oxygen atoms to vacancies or other solutes in this complex system [38] will impact the kinetics. The apparently increased oxygen content, coupled with the possibility of increased diffusion and associated kinetics due to the vacancy supersaturation, apparently allows the oxygen to diffuse to the NCs and increase their oxygen content towards that of the stoichiometric oxygen content of the equilibrium $\mathrm{Ti}_{2} \mathrm{Y}_{2} \mathrm{O}_{7}$ precipitate $(63.6 \%)$.

The exact value of the oxygen, and other solutes, in these ultrafine NCs is imprecise, due to trajectory aberrations and the precise nature of the interface and possible disordered or amorphous nature of the NCs [39]. The increase of oxygen in the NCs from the BM to the other zones is likely real, but the apparent increase in oxygen (or other solute) content from the smaller to the larger NCs is difficult to know with precision. This is a fundamental limitation of APT. 
The observation of the oxygen content increase is vital to interpret future radiation or mechanical properties studies. Mechanistically, increasing oxygen may result in different radiation tolerance of the NCs, different abilities of the NC/matrix interface to absorb radiation-induced point defects, and possibly different action as dislocation obstacles to control mechanical properties. To verify the variation of oxygen from APT results, complementary analysis were performed using XPS measurements. Comparative oxygen profiles from the surface of both as-welded and PWHT were plotted in Fig 8. A decrease of oxygen is clearly observed from the surface in both the cases. Almost no variation of the oxygen percentage was observed near the surface for both the samples, however, probing deeper into the surface, to almost a micron depth, revealed a comparatively higher content of oxygen in the as-welded sample. We speculate that the reason for this difference could be attributed to the sequence of analysis between the two samples. Both the samples were loaded into the vacuum chamber and the as-welded sample was analyzed first resulting in better vacuum conditions for PWHT, thereby lowering the zero level. Although this result differs in a way from APT results we believe this is due to the inhomogeneous distribution within the material. It must be noted that the analysis volume was very different in either case, for XPS a $400 \times 400 \mu \mathrm{m}^{2}$ area (approximately 1-2 $\mu \mathrm{m}$ deep, i.e., $\sim 10^{5} \mu^{3}$ ) was analyzed whereas in APT maximum volume of $1 \mu \mathrm{m}^{3}$ was analyzed. So the comparison between these two results doesn't give any conclusive evidence of oxygen enrichment in PWHT, and further studies need to be performed to understand the effect of heating.

\section{Conclusion}

To understand the microstructural development during FSW in a 14YWT NFA alloy, three microstructurally distinct regions, (the BM, SZ and TMAZ) have been studied in detail by APT. The following conclusions were reached:

1) Although the mean radius appeared to increase slightly in the SZ and TMAZ compared to the $\mathrm{BM}$ in both the as-FSW, and to a smaller extent, in the PWHT conditions, the large standard deviations indicated that there were no statistical differences between any of the size estimates in 
the present test condition, in contrast to the traditional fusion welding processes. Small differences were observed in the shape of the size distributions' histograms.

2) After the PWHT, the number density of the NCs increased significantly. This increase is attributed to nucleation and growth of new NCs that grow to become detectable during the PWHT. The new particles likely nucleated from the solute- and vacancy-enriched as-FSW structure.

3) To drive the clearly non-equilibrium as-FSW state closer toward equilibrium, a PWHT may be required.

4) The FSW process appears to be a viable technique for joining NFAs in terms of maintaining NCs in the welds.

\section{Acknowledgements}

Research sponsored by the Materials Sciences and Engineering Division, Office of Basic Energy Sciences, US Department of Energy. APT was conducted as part of a user project at the Center for Nanophase Materials Sciences, which is a DOE Office of Science User Facility. FSW was made as part of DOE Fusion Energy Program.

\section{References}

[1] G. R. Odette, M. J. Alinger and B. D. Wirth, Ann. Rev. Mater. Res., 38 (2008) 471-503.

[2] M. K. Miller, K. F. Russell, D. T. Hoelzer, J. Nucl. Mater. 351 (2006) 261-268.

[3] A. Certain, K. G. Field, T. R. Allen, M. K. Miller, J. Bently and J. T. Busby, J. Nucl. Mater., 407 (2010) 2-9.

[4] K. L. Murty and I. Charit, J. Nucl. Mater., 383 (2008) 189-195.

[5] J. He, F. Wan, K. Sridharan, T. R. Allen, A. Certain, V. Shutthanandan and Y. Q. Wu, J. Nucl. Mater., 455 (2014) 41-45.

[6] M.J. Alinger, G.R. Odette, D.T. Hoelzer, Acta Materialia, 57 (2009) 392-406. 
[7] E. Gaganidze and J. Aktaa, 88 (2013) 118-128.

[8] R. Lindau, A. Möslang, M. Rieth, M. Klimiankou, E. Materna-Morris, A. Alamo, A.A.F. Tavassoli, C. Cayron, A.M. Lancha, P. Fernandez, N. Baluc, R. Schäublin, E. Diegele, G. Filacchioni, J.W. Rensman, B.v.d. Schaaf, E. Lucon, W. Dietz, 75-79 (2005) 989-996.

[9] S. Noh, R. Kasada, A. Kimura, S.H.C. Park, S. Hirano, J. Nucl. Mater., 417 (2011) 245-248.

[10] B. Mazumder, C.M. Parish, H. Bei, and M. K. Miller, J.Nucl.Mater., 465, 204-211

[11] H. D. Hedrich, H. G. Mayer, G. Haufler, M. Kopf and N. Reheis, ASME 1991 International Gas Turbine and Aeroengine Congress and Exposition, 5 (1991) V005T12A016.

[12] C. L. Chen, G.J. Tatlock, A. R. Jones, J. Alloys Compd., 504 (1) (2010) S460-S466.

[13] W. Han, F. Wan, B. Leng, S. Ukai, Q. Tang, S. Hayashi, J. He, Y. Sugino, Sci. Technol. Weld. Join., 16 (2011) 690-696.

[14] M. H. Mathon, V. Klosek, Y. de Carlan, L. Forest, J. Nucl. Mater., 386-388 (2009) 475-478.

[15] F. Legendre, S. Poissonnet, P. Bonnaillie, L. Boulanger, L. Forest, J. Nucl. Mater., 386-388 (2009) 537-539.

[16] J. Wang,W. Yuan, R. S.Mishra and I. Charit, J. Nucl. Mater., 432 (2013) 274-280.

[17] R. S. Mishra, Z. Y. Ma, Mater. Sci. Engin. R, 50 (2005) 1-78.

[18] A. Etienne, N. J. Cunningham, Y. Wu, and G. R, Odette, Mat. Sci. Tech., 27 (4) (2011) 724728.

[19] B. W. Baker, T. R. McNelley and L. N. Brewer, Mat. Sc. Eng. A, 589(0) (2014) 217-227.

[20] B.W. Baker and L. N. Brewer, J. Microsc., 66(12) (2014) 2442-2457.

[21] D. T. Hoelzer, K. A. Unocic, M. A. Sokolov and Z. Feng, J. Nucl. Matter., 442 (2013) S529-S534.

[22] C. L. Chen, P. Wang, and G. J. Tatlock, Mat. High Temp., 26(3) (2009) 299-303.

[23] D.A. McClintock, D.T. Hoelzer, M.A. Sokolov, R.K. Nanstad, J. Nucl. Mater. 386-388 (2009) 307-311

[24] M. K. Miller and R.G. Forbes, “Atom Probe Tomography: The Local Electrode Atom Probe" Springer publications 2014

[25] T. J. Lienert, W. L. Stellwag Jr., B. B. Grimmett, R. M. Warke, Weld. J., 82 (1) (2003) 1s. [26] X. Yu, B. Mazumder, M. K. Miller, S. A. David and Z. Feng, Sci. Technol. Weld. Join., 20 
(2015) 236-241.

[27] M.K. Miller, C.M. Parish, Materials Science and Technology, 27 (2011) 729-734.

[28] W. T. Han, F. R. Wan, B. Leng, S. Ukai, Q. X. Tang, S. Hayashi, J. C. He and Y. Sugino, Sci. Technol. Weld. Join., 16 (2011) 690-696.

[29] J. Wang, W. Yuan, R. S. Mishra and I. Charit, J. Nucl. Matter., 442 (2013) 1-6.

[30] C. M. Parish, P. D. Edmondson, Y. Zhang and M. K. Miller, J. Nucl. Matter., 418 (2011)106-109.

[31] T. R. Allen, J. Gan, J. I. Cole, M. K. Miller, J. T. Busby, S. Shutthanandan and S.

Thevuthasan, J. Nucl. Matter., 375 (2008) 26-37.

[32] M. K. Miller, C. M. Parish and H. Bei , J. Nucl. Matter., 462 (2015) 422-427

[33] C. M. Parish, R. M. White, J. M. LeBeau, and M. K. Miller, J. Nucl. Mater., 445(1-3) (2014) 251-260

[34] S. J. Zinkle, and L. L. Snead, Ann. Rev. Mater. Res., 44(1) (2014) 241-267.

[35] M. C. Brandes, L. Kovarik, M. K. Miller, G .S. Daehn, and M. J. Mills, Acta Mater., 50 (2011) 1827-1839.

[36] N. B. Camilli, "Simulations of Ti-Y-O Nanoclusters in Ferritic Alloys" Master's Thesis, University of Tennessee, 2013. http://trace.tennessee.edu/utk_gradthes/1599.

[37] E. D. Hondros, Phys. Stat. Sol., 21 (1967) 375-382

[38] C.L. Fu, M. Krcmar, G.S. Painter, X.Q. Chen, Vacancy mechanism of high oxygen solubility and nucleation of stable oxygen-enriched clusters in Fe, Physical Review Letters, 99 (2007).

[39] M.C. Brandes, L. Kovarik, M.K. Miller, M.J. Mills, Morphology, structure, and chemistry of nanoclusters in a mechanically alloyed nanostructured ferritic steel, Journal of Materials Science, 47 (2012) 3913-3923.

[40] R. Nandan, T. DebRoy, H. K. D. H. Bhadeshia, Prog. Mater. Sci., 53 (2008) 980-1023. 
Tables:

Table 1: Composition of 14YWT NFA. The balance is Fe.

\begin{tabular}{c|ccccccccc}
\hline 14YWT & & $\mathrm{Cr}$ & $\mathrm{Y}$ & $\mathrm{W}$ & $\mathrm{Ti}$ & $\mathrm{O}$ & $\mathrm{C}$ & $\mathrm{Si}$ & $\mathrm{N}$ \\
& at. \% & 13.93 & 0.14 & 0.16 & 0.24 & 0.39 & 0.24 & 0.16 & 0.15 \\
& wt. \% & 13.13 & 0.22 & 0.54 & 0.19 & 0.12 & 0.05 & 0.08 & 0.04 \\
\hline
\end{tabular}

Table 2: Composition of F82H steel. The balance is Fe. Note the distinctly lower Cr level compared to the 14YWT NFA.

\begin{tabular}{c|ccccccccc}
\hline F82H & & $\mathrm{Cr}$ & $\mathrm{Mn}$ & $\mathrm{W}$ & $\mathrm{V}$ & $\mathrm{Al}$ & $\mathrm{C}$ & $\mathrm{Si}$ & $\mathrm{N}$ \\
& at. \% & 8.02 & 0.50 & 0.61 & 0.22 & 0.04 & 0.47 & 0.28 & 0.008 \\
& wt. \% & 7.44 & 0.49 & 2.00 & 0.2 & 0.02 & 0.10 & 0.14 & 0.002 \\
\hline
\end{tabular}

Table 3: Estimates of the size and number density of the precipitates in the BM, SZ and TMAZ regions in the 14YWT NFA for both the as-FSW and after the PWHT conditions

\begin{tabular}{lcccl}
\hline Zone & \multicolumn{2}{c}{ Number density $\left(\times 10^{22} \mathrm{~m}^{-3}\right)$} & \multicolumn{2}{c}{ NC size $(\mathrm{nm})$} \\
\hline & As-FSW & $P W H T$ & $A s-F S W$ & $P W H T$ \\
BM & $5 \pm 2$ & $5 \pm 2$ & $1.9 \pm 0.6$ & $1.6 \pm 0.8$ \\
SZ & $2 \pm 2$ & $20 \pm 10$ & $2.8 \pm 1.6$ & $2.0 \pm 1.1$ \\
TMAZ & $6 \pm 3$ & $9 \pm 3$ & $2.9 \pm 1.4$ & $2.3 \pm 1.5$ \\
\hline
\end{tabular}


Table 4: The parameters of the size distributions of the all the precipitates in the BM, SZ and TMAZ regions in the 14YWT NFA for both the as-FSW and the PWHT conditions

\begin{tabular}{c|cccccc}
\hline \multirow{2}{*}{} & \multicolumn{2}{|c}{ Base metal } & \multicolumn{2}{c}{ Stir zone } & \multicolumn{2}{c}{ TMAZ } \\
\cline { 2 - 7 } No. of & As-FSW & PWHT & As-FSW & PWHT & As-FSW & PWHT \\
particles & 128 & 67 & 1824 & 84 & 617 & 174 \\
Mean & $1.9 \pm 0.6$ & $1.6 \pm 0.8$ & $2.8 \pm 1.6$ & $2.0 \pm 1.1$ & $2.9 \pm 1.4$ & $2.3 \pm 1.5$ \\
Mode & 1.56 & 1.0 & 1.63 & 0.83 & 1.58 & 1.94 \\
Median & 1.76 & 1.4 & 2.38 & 1.8 & 2.63 & 1.94 \\
Min. & 0.90 & 0.5 & 0.71 & 0.55 & 0.92 & 0.52 \\
Max. & 4.29 & 4.36 & 18.02 & 7.5 & 11.01 & 10.4 \\
Skewness & 1.18 & 1.07 & 3.26 & 1.42 & 1.87 & 1.85 \\
Kurtosis & 1.35 & 0.86 & 24.00 & 3.95 & 5.38 & 5.68 \\
\hline
\end{tabular}

Table 5: Average overall compositions in atomic percent of BM, SZ and TMAZ regions in the 14YWT NFA for the as-FSW and PWHT conditions, as estimated from APT measurements

\begin{tabular}{l|llllll}
\hline $\boldsymbol{A s}$ - $\boldsymbol{F S W}$ & $\mathbf{C r}$ & $\mathbf{W}$ & $\mathbf{O}$ & $\mathbf{T i}$ & $\mathbf{Y}$ & $\mathbf{C}$ \\
Base metal & $14.52 \pm 0.01$ & $0.54 \pm 0.01$ & $0.31 \pm 0.01$ & $0.34 \pm 0.01$ & $0.12 \pm 0.01$ & $0.15 \pm 0.01$ \\
Stir zone & $14.60 \pm 0.01$ & $0.56 \pm 0.01$ & $0.25 \pm 0.01$ & $0.33 \pm 0.01$ & $0.09 \pm 0.01$ & $0.015 \pm 0.01$ \\
TMAZ & $14.63 \pm 0.01$ & $0.60 \pm 0.01$ & $0.37 \pm 0.01$ & $0.53 \pm 0.01$ & $0.14 \pm 0.01$ & $0.22 \pm 0.01$ \\
$\boldsymbol{P W H T}$ & & & & & & \\
Base metal & $14.03 \pm 0.01$ & $0.2 \pm 0.001$ & $0.94 \pm 0.01$ & $0.1 \pm 0.001$ & $0.07 \pm 0.001$ & $0.09 \pm 0.01$ \\
Stir zone & $13.50 \pm 0.01$ & $0.13 \pm 0.001$ & $0.88 \pm 0.001$ & $0.26 \pm 0.001$ & $0.06 \pm 0.001$ & $0.05 \pm 0.01$ \\
TMAZ & $14.13 \pm 0.004$ & $0.23 \pm 0.002$ & $0.84 \pm 0.002$ & $0.24 \pm 0.001$ & $0.14 \pm 0.001$ & $0.05 \pm 0.01$ \\
\hline
\end{tabular}


Table 6: $\mathrm{Y}:(\mathrm{Ti}+\mathrm{O})$ ratios from $\mathrm{BM}, \mathrm{SZ}$ and TMAZ regions in the 14YWT NFA for the as-FSW and PWHT conditions

\begin{tabular}{c|cc}
\hline $\boldsymbol{Y : ( T i + O )}$ & $\boldsymbol{A s - F S W}$ & $\boldsymbol{P W H T}$ \\
\hline Base metal & 0.18 & 0.07 \\
Stir zone & 0.15 & 0.05 \\
TMAZ & 0.15 & 0.13 \\
\hline
\end{tabular}

Table 7: Average composition of NCs in the BM, SZ and TMAZ regions of the 14YWT NFA for the PWHT condition based on the total number of atoms within the volumes extracted from all the isosurfaces.

\begin{tabular}{l|c|ccccc}
\hline Zone & At. \% & Cr & O & Ti & Y & C \\
\hline Base metal & (2-4 nm cluster) & $17.6 \pm 0.8$ & $19.2 \pm 2.8$ & $10.8 \pm 1.7$ & $7.5 \pm 1.5$ & $0.3 \pm 0.2$ \\
\hline \multirow{2}{*}{ Stir zone } & (2-4 nm cluster) & $18.4 \pm 2.5$ & $22.0 \pm 4.7$ & $11.2 \pm 2.2$ & $8.1 \pm 2.5$ & $0.4 \pm 0.3$ \\
& (4-6 nm cluster) & $14.9 \pm 2.4$ & $28.3 \pm 6.4$ & $13.0 \pm 2.8$ & $10.6 \pm 3.5$ & $0.5 \pm 0.3$ \\
\multirow{2}{*}{ TMAZ } & (2-4 nm cluster) & $18.2 \pm 2.9$ & $23.3 \pm 5.2$ & $15.3 \pm 2.9$ & $7.3 \pm 2.2$ & $0.4 \pm 0.3$ \\
& (4-6 nm cluster) & $13.4 \pm 3.3$ & $28.3 \pm 7.6$ & $14.7 \pm 3.4$ & $11.6 \pm 4.4$ & $0.4 \pm 0.3$ \\
\hline
\end{tabular}

Table 8: $\mathrm{Y}$ :(Ti+O) ratios from five different clusters $\left(\mathrm{C}_{1}, \mathrm{C}_{2}, \mathrm{C}_{3}, \mathrm{C}_{4}, \mathrm{C}_{5}\right)$ and the average $\mathrm{C}_{\text {avg. }}$ from the BM, SZ and TMAZ regions in the 14YWT NFA for the as-FSW and PWHT conditions

\begin{tabular}{|c|c|c|c|c|c|c|c|c|c|c|c|c|}
\hline \multirow[t]{2}{*}{$Y:(T i+O)$} & \multicolumn{5}{|c|}{$A s-F S W$} & \multirow{2}{*}{$\begin{array}{l}\text { Avg } \\
C_{\text {avg }}\end{array}$} & \multicolumn{5}{|c|}{$P W H T$} & \multirow{2}{*}{$\frac{A v g}{C_{\text {avg }}}$} \\
\hline & $\mathrm{C}_{1}$ & $\mathrm{C}_{2}$ & $\mathrm{C}_{3}$ & $\mathrm{C}_{4}$ & $\mathrm{C}_{5}$ & & $\mathrm{C}_{1}$ & $\mathrm{C}_{2}$ & $\mathrm{C}_{3}$ & $\mathrm{C}_{4}$ & $\mathrm{C}_{5}$ & \\
\hline Base metal & 0.19 & 0.18 & 0.12 & 0.21 & 0.2 & 0.18 & 0.3 & 0.23 & 0.14 & 0.2 & 0.2 & 0.21 \\
\hline Stir zone & 0.17 & 0.12 & 0.14 & 0.12 & 0.22 & 0.15 & 0.26 & 0.2 & 0.15 & 0.16 & 0.17 & 0.19 \\
\hline TMAZ & 0.08 & 0.19 & 0.3 & 0.04 & 0.18 & 0.16 & 0.13 & 0.14 & 0.14 & 0.10 & 0.11 & 0.12 \\
\hline
\end{tabular}


Figures:

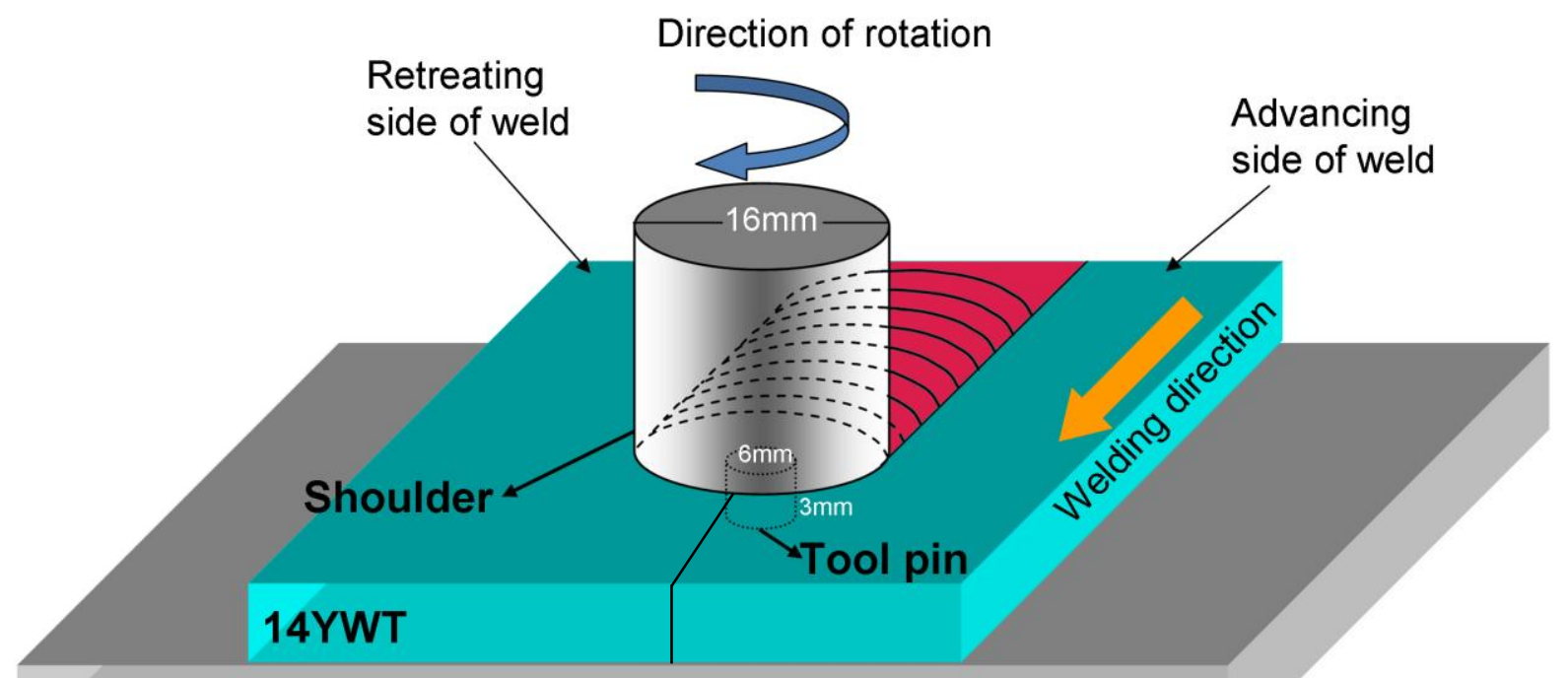

\section{F82H}

Figure 1: Schematic illustration of the friction-stir welding process after [40]. A F82H base plate was used due to the limited thickness of the 14YWT plates. 


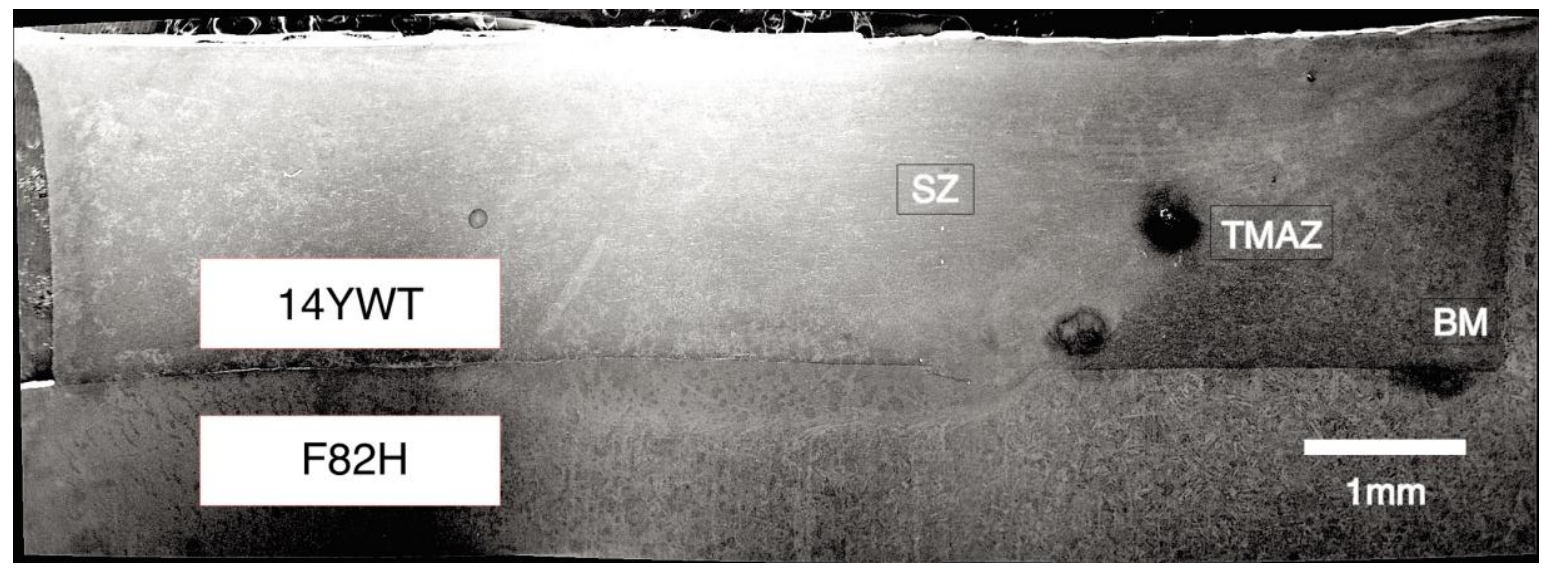

Fig 2: (a) Scanning electron microscope image of a cross section of the FSW of the 14YWT NFA showing the three regions representative of the BM, the SZ, and the TMAZ. 
(a) Base metal

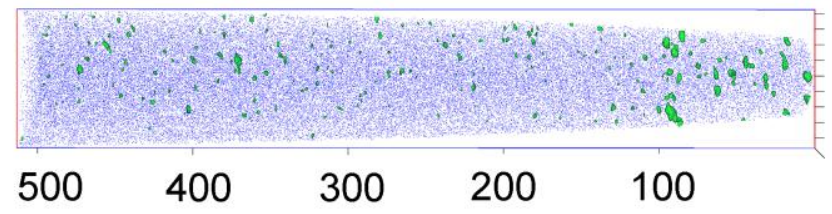

(b) Stir zone

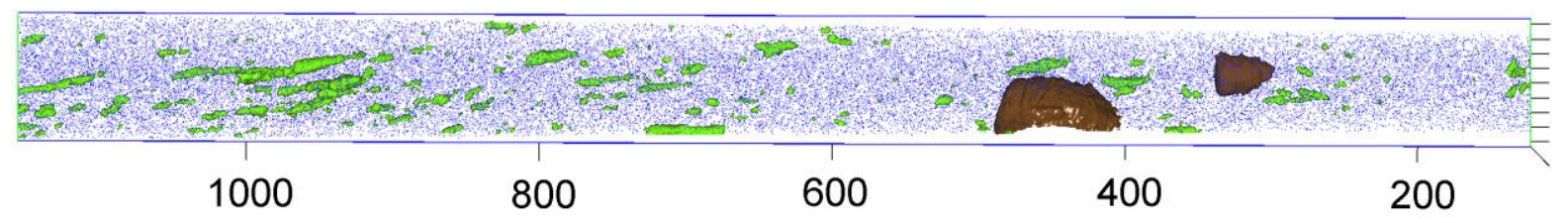

(c) Thermomechanically affected zone

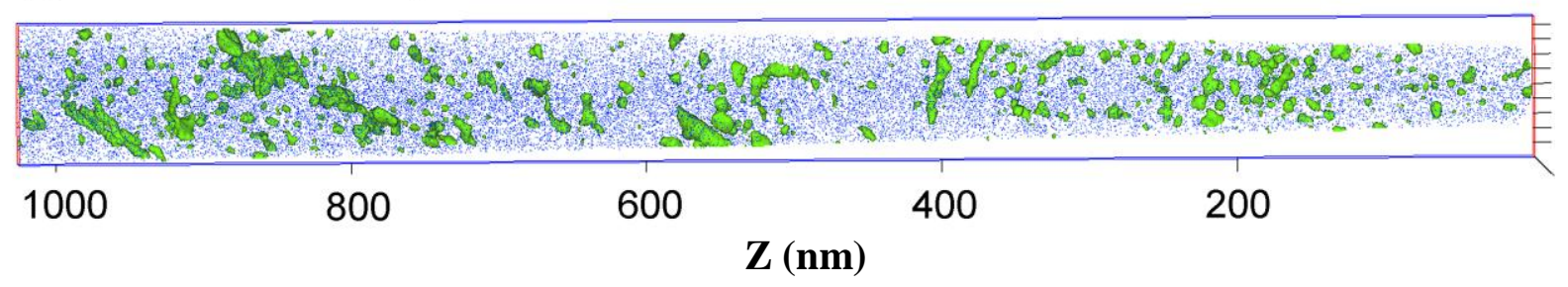

Figure 3: As-FSW sample: 5\% Ti concentration isosurfaces of (a) BM, (b) SZ, and (c) TMAZ and showing the distribution of the Fe atoms (blue), Ti-Y-O-enriched NCs (green isosurface) and the $\operatorname{Ti}(\mathrm{O}, \mathrm{C}, \mathrm{N})$ precipitates (brown isosurface). 
(a) Base metal

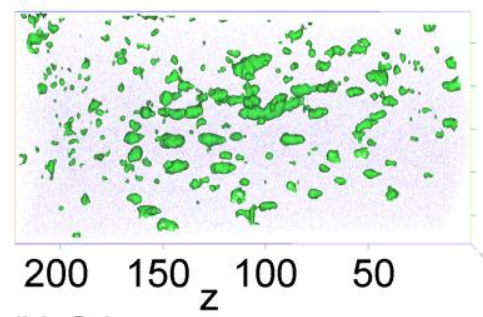

(b) Stir zone

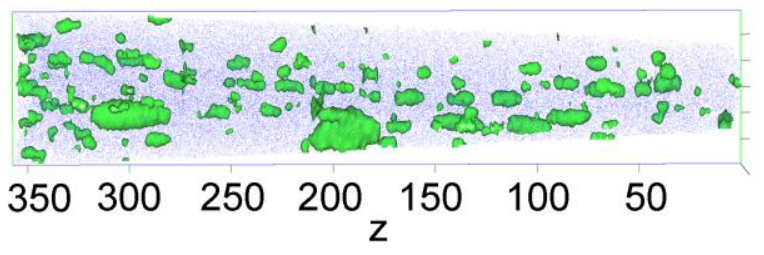

(c) Thermomechanically affected zone

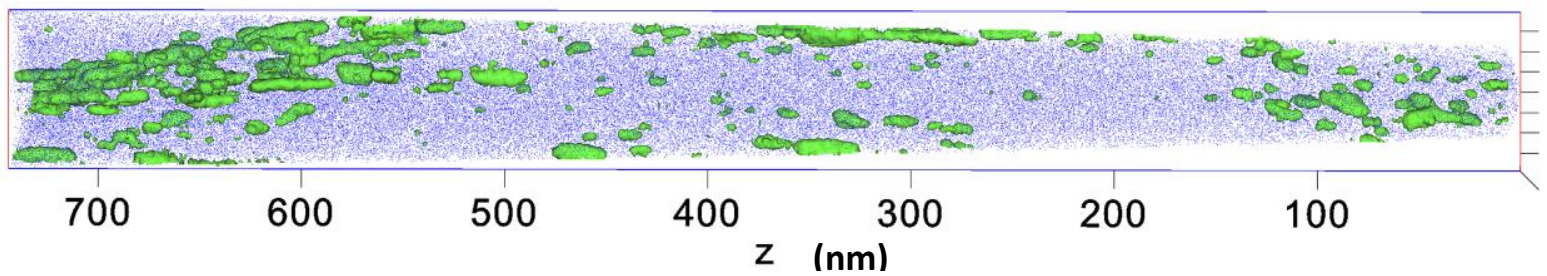

Figure 4: FSW and post weld heat treated sample: $3 \%$ Ti concentration isosurfaces of (a) BM, (b) SZ, and (c) TMAZ showing the distribution of the Fe atoms (blue) and Ti-Y-O NCs and precipitates (green isosurface) 

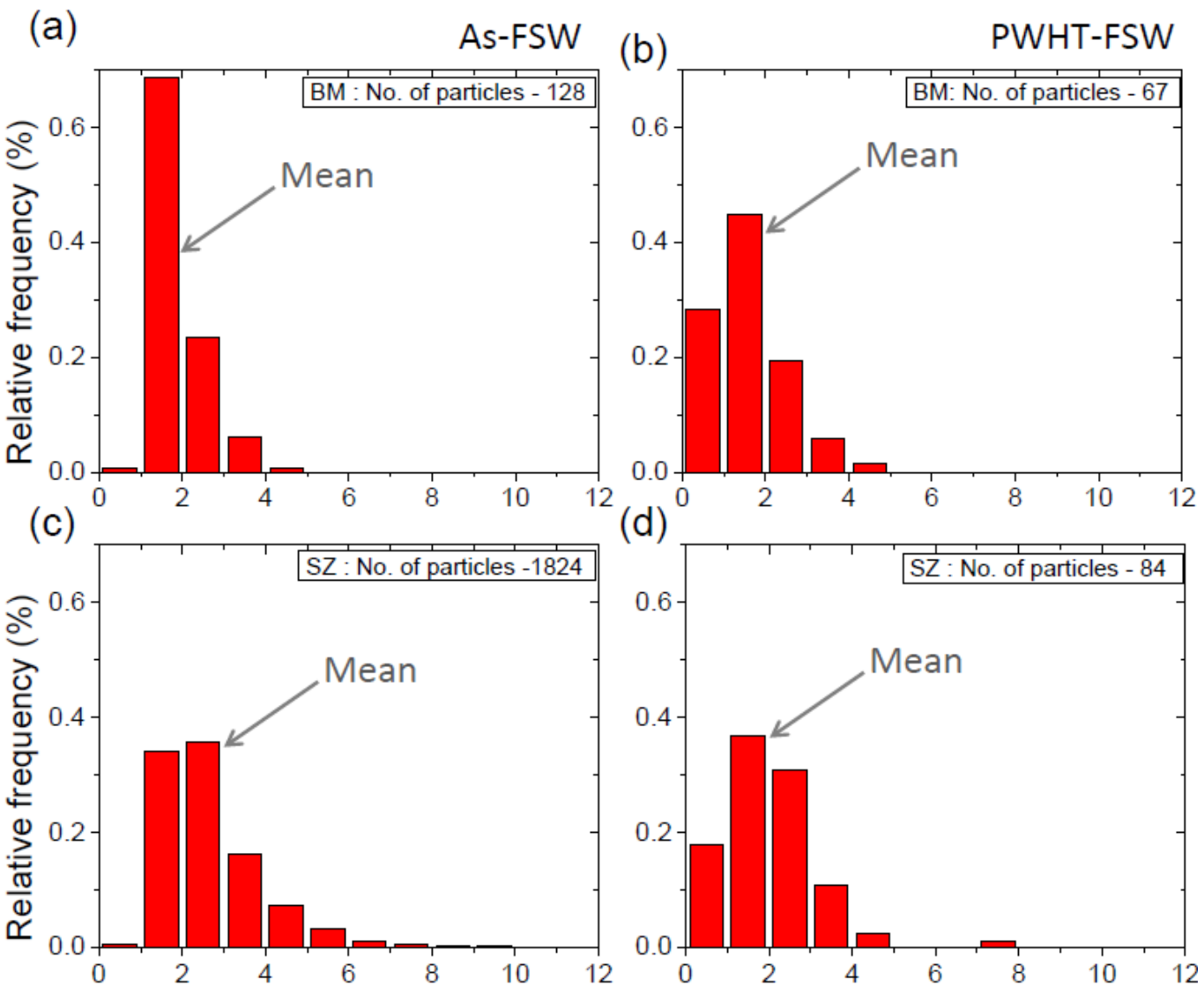

(e)

(f)
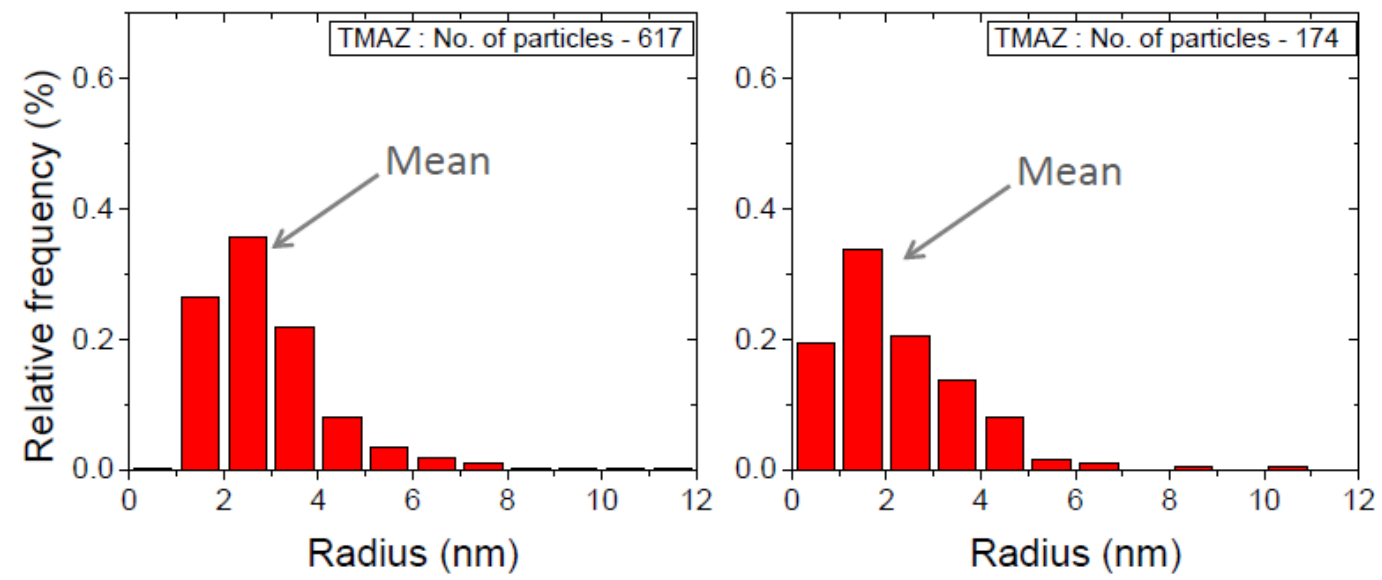

Figure 5: Size distributions of the NCs for the BM, SZ and TMAZ for both the as-FSW and PWHT samples. After the PWHT, the precipitate size has decreased for both the TMAZ and the SZ zone, whereas no significant change was observed for BM zone 


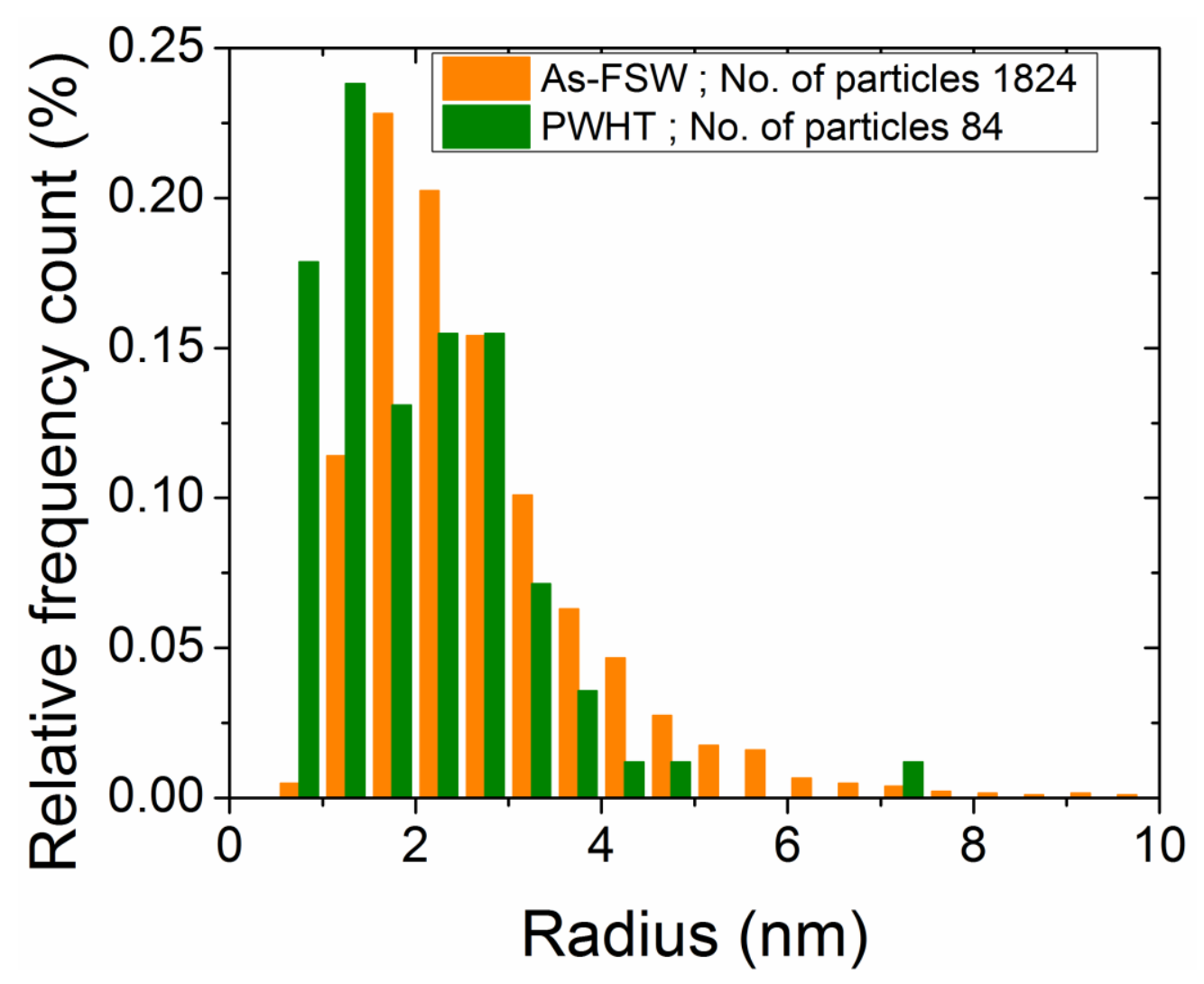

Figure 6: Size distribution of the precipitates for both as-FSW and PWHT condition from the SZ showing a wider distribution for as-FSW condition and a decrease in the NC size after the PWHT. 
(a)

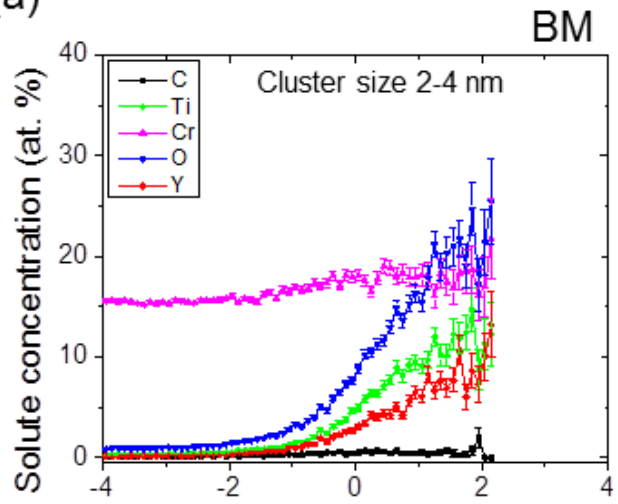

(b)

(c)
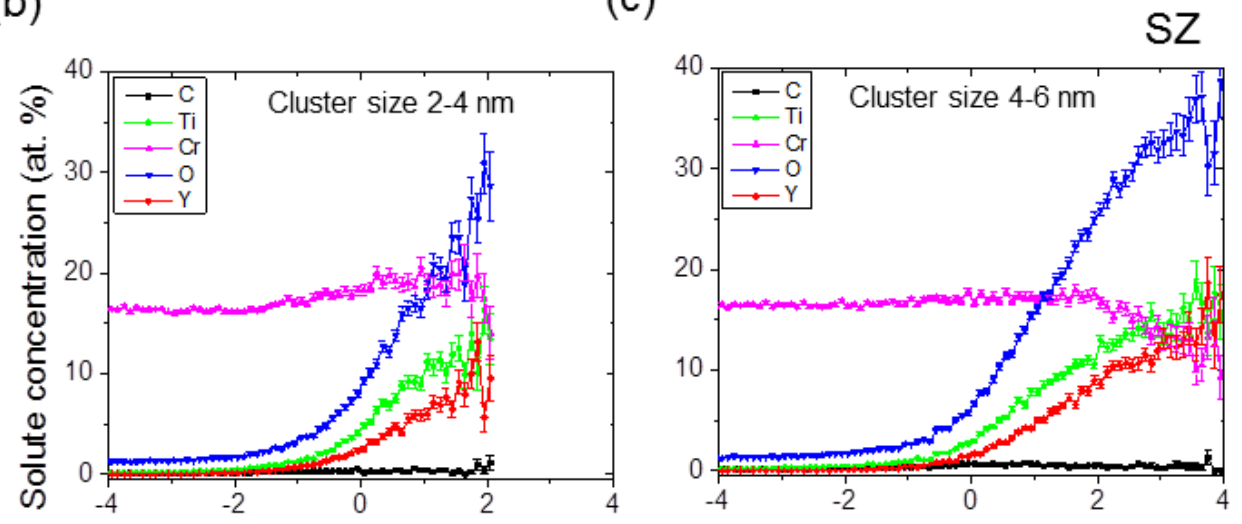

(d)

(e)

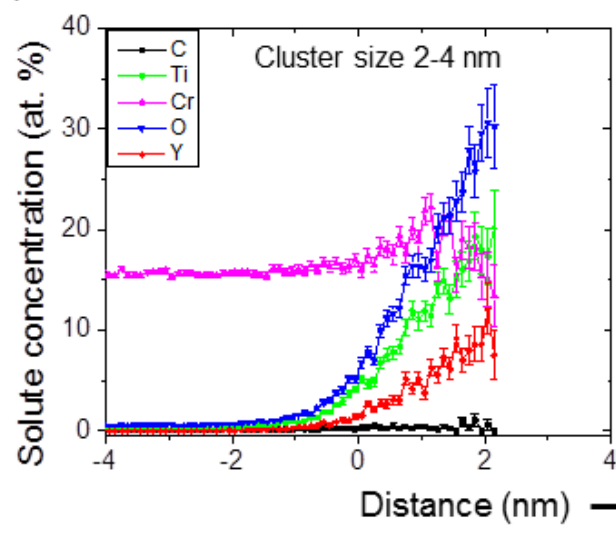

TMAZ

Figure 7: APT proximity histograms from the FSW after the PWHT showing the solute partitioning of Ti, $\mathrm{Y}, \mathrm{O}, \mathrm{Cr}$, and $\mathrm{C}$ between the ferrite phase and the smaller 2-4 $\mathrm{nm}$ and larger 4$6 \mathrm{~nm}$ Ti-Y-O-enriched NCs from the BM, SZ and TMAZ regions. 


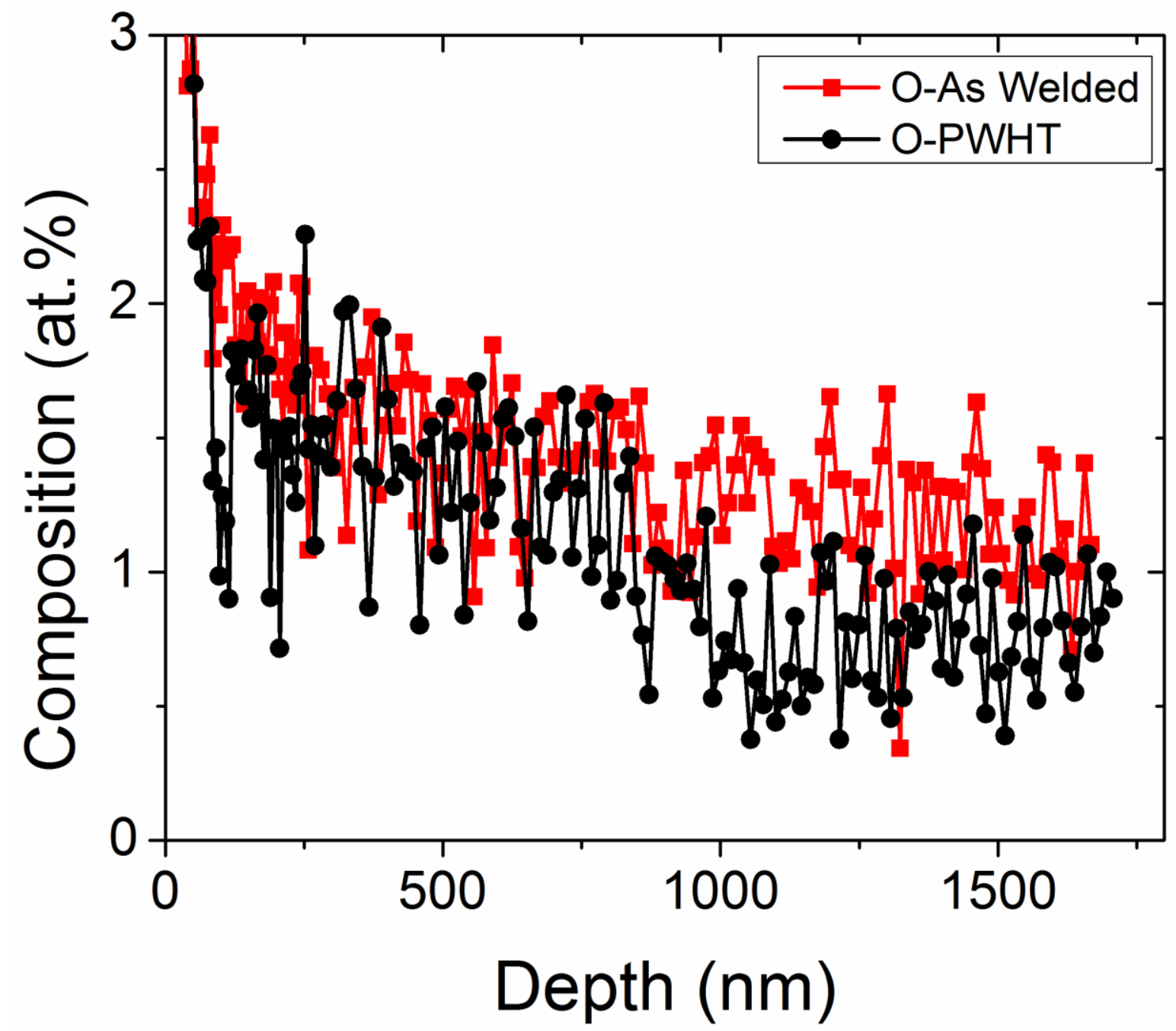

Figure 8: Oxygen depth profile obtained from XPS measurement from both the as-welded (red) and PWHT (black) 